\title{
Genetic issues in the diagnosis of dystonias
}

\author{
Simona Petrucci ${ }^{1,2}$ and Enza Maria Valente ${ }^{1,3}$ * \\ ${ }^{1}$ Neurogenetics Unit, CSS-Mendel Laboratory, IRCCS Casa Sollievo della Sofferenza, San Giovanni Rotondo, Italy \\ 2 Department of Experimental Medicine, "Sapienza" University of Rome, Rome, Italy \\ ${ }^{3}$ Department of Medicine and Surgery, University of Salerno, Salerno, Italy
}

\section{Edited by:}

Maria Fiorella Contarino, Academic Medical Center, Netherlands

Reviewed by:

Deborah Hall, Rush University, USA Francesca Morgante, University of Messina, Italy

\section{*Correspondence:}

Enza Maria Valente, Neurogenetics Unit, CSS-Mendel Institute, Viale Regina Margherita 261, 00198 Rome, Italy.

e-mail:e.valente@css-mendel.it
Dystonias are heterogeneous hyperkinetic movement disorders characterized by involuntary muscle contractions which result in twisting and repetitive movements and abnormal postures. Several causative genes have been identified, but their genetic bases still remain elusive. Primary Torsion Dystonias (PTDs), in which dystonia is the only clinical sign, can be inherited in a monogenic fashion, and many genes and loci have been identified for autosomal dominant (DYT1/TOR1A; DYT6/THAP1; DYT4/TUBB4a; DYT7; DYT13; DYT21; DYT23/CIZ1; DYT24/ANO3; DYT25/GNAL) and recessive (DYT2; DYT17) forms. However most sporadic cases, especially those with late-onset, are likely multifactorial, with genetic and environmental factors interplaying to reach a threshold of disease. At present, genetic counseling of dystonia patients remains a difficult task. Recently non-motor clinical findings in dystonias, new highlights in the pathophysiology of the disease, and the availability of high-throughput genome-wide techniques are proving useful tools to better understand the complexity of PTD genetics. We briefly review the genetic basis of the most common forms of hereditary PTDs, and discuss relevant issues related to molecular diagnosis and genetic counseling.

Keywords: dystonia, genetic, diagnosis, DYT1, DYT6, non-motor, phenotype, counseling

\section{INTRODUCTION}

Dystonias are a heterogeneous group of hyperkinetic movement disorders characterized by involuntary muscle contractions, resulting in twisting and repetitive movements and abnormal postures (Fahn, 1988). Although the diagnosis is mainly clinical (Albanese and Lalli, 2012), the current classification is based on etiology, distinguishing primary torsion dystonias (PTDs), dystoniaplus syndromes, heredodegenerative disorders and secondary dystonias (Bressman, 2004). With the exclusion of secondary forms which are related to acquired causes, dystonic syndromes have a genetic basis. Several genes and loci have been identified (named with the conventional DYT symbol followed by progressive numbers - see Table 1), yet a genetic diagnosis remains elusive in the majority of patients. This review will focus on PTDs, tackling current achievements, and challenges in genetic diagnosis.

\section{THE COBWEB OF PTDS}

In PTDs, dystonia is the only clinical sign (apart of tremor), without evidence of identifiable exogenous causes or neurodegeneration. PTDs represent the third most common movement disorder after Parkinson's disease (PD) and essential tremor, and include about $75 \%$ of dystonia cases (Phukan et al., 2011). The clinical spectrum is broad and there is often a strong relationship between age at onset and clinical severity. In early-onset PTDs, dystonia usually generalizes within $5-10$ years while, in late-onset forms, dystonia tends to remain focal or segmental (Ozelius and Bressman, 2011). A substantial proportion of early-onset cases ( $<26$ years) have a monogenic basis with autosomal dominant (AD) or, more rarely, recessive (AR) inheritance (Table 1). Conversely, late-onset PTDs are complex disorders in which genetic and environmental risk factors variably interplay to determine the phenotype (Defazio et al., 2007). Yet this paradigm does not always hold true in atypical cases where blurred clinical signs and overlapping phenotypes can make genetic diagnosis a difficult task.

\section{AUTOSOMAL DOMINANT PTD}

DYT1-dystonia is the most common form of early-onset PTD, with an estimated frequency of 1/9,000 in Ashkenazi Jewish population and 1/160,000 worldwide (Bressman et al., 2000). A recurrent 3 bp deletion (delGAG) in the TOR1A (TorsinA) gene on chromosome $9 \mathrm{q} 34.11$ is found in nearly all mutated cases (Ozelius et al., 1997). The delGAG results in a glutamic acid residue loss in the C-terminus conserved region of Torsin A protein; mutant TorsinA shows aberrant cellular localization and impaired interaction with other proteins, resulting in stress-induced abnormalities, synaptic vesicle recycling defects, and altered development of neuronal pathways (Granata and Warner, 2010).

This mutation is found in diverse ethnicities, either inherited as a founder mutation or - de novo (Klein et al., 1998; Ozelius and Bressman, 2011), and only two additional mutations of unclear pathogenicity (p.R288Q and p.F205I) have been described in isolated atypical cases (Zirn et al., 2008; Calakos et al., 2010). The delGAG is inherited as an AD trait and only $20-30 \%$ of mutation carriers develop the disease (incomplete penetrance); interestingly, penetrance appears to be markedly lower $(\sim 3 \%)$ in patients carrying the p.D216H polymorphism (rs1801968), suggesting that this variant could act as a genetic modifier of the delGAG mutation (Kamm et al., 2008). In most cases DYT1-dystonia starts during childhood in a limb, with generalization occurring within 
Table 1 | Molecular classification of "DYT" dystonia syndromes.

\begin{tabular}{|c|c|c|c|c|}
\hline Disease (MIM) & Gene & Locus & Phenotype & Inheritance \\
\hline \multicolumn{5}{|c|}{ PURE PRIMARY TORSION DYSTONIA } \\
\hline DYT1 (128100) & TOR1A & $9 q 34$ & Early-onset generalized limb onset dystonia & $A D$ \\
\hline DYT4 (128101) & TUBB4a & $19 p 13.12-13$ & Whispering dysphonia & $A D$ \\
\hline DYT13 (607671) & - & $1 p 36.32-p 36.13$ & Cervical and upper-limb dystonia & $A D$ \\
\hline DYT17 (612406) & - & $20 p 11.2-q 13.12$ & Segmental or generalized dystonia with prominent dysphonia & $A R$ \\
\hline DYT21 (614588) & - & $2 q 14.3-q 21.3$ & $\begin{array}{l}\text { Adult-onset generalized or multifocal dystonia, often starting with } \\
\text { blepharospasm }\end{array}$ & $A D$ \\
\hline DYT23 (614860) & $\mathrm{ClZ1}$ & $9 q 34$ & Adult-onset cervical dystonia & $A D$ \\
\hline THD (605407) & $\mathrm{TH}$ & $11 \mathrm{p} 15.5$ & Dopa-responsive dystonia & $A R$ \\
\hline DYT11 (159900) & SGCE & $7 q 21.3$ & Myoclonus-dystonia & $A D$ \\
\hline DYT12 (128235) & ATP1A3 & $19 q 13.2$ & Rapid-onset dystonia parkinsonism & $A D$ \\
\hline DYT15 (607488) & - & $18 p 11$ & Myoclonus-dystonia & $A D$ \\
\hline DYT16 (612067) & PRKRA & $2 q 31.2$ & Early-onset dystonia parkinsonism & $A R$ \\
\hline \multicolumn{5}{|c|}{ PAROXYSMAL SYNDROME } \\
\hline DYT8 (118800) & MR1 & $2 q 35$ & Paroxysmal non-kinesigenic dyskinesia (PNKD) & $A D$ \\
\hline $\begin{array}{l}\text { DYT9 (601042)/DYT18 } \\
\text { (612126) }\end{array}$ & $S L C 2 A 1$ & $1 \mathrm{p} 34.2$ & $\begin{array}{l}\text { Paroxysmal dyskinesias with episodic ataxia and } \\
\text { spasticity/paroxysmal exercise-induced dystonia (PED) }\end{array}$ & $A D$ \\
\hline DYT10 (128200) & PRRT2 & $16 p 11.2$ & Paroxysmal kinesigenic dyskinesia (PKD) & $A D$ \\
\hline
\end{tabular}

$A D$, autosomal dominant; AR autosomal recessive: $X-R, X$ linked recessive. ${ }^{*} D Y T 7$ locus on chromosome 18p has been recently questioned Winter et al., 2012).

a few years from onset, but usually sparing the cranial-cervical region. More rarely, dystonia may remain segmental or purely focal (Ozelius and Bressman, 2011). Overall, clinical manifestations can vary widely even within families, ranging from dystonic storm to mild writer's cramp (Opal et al., 2002; Edwards et al., 2003).

DYT6-dystonia is also a pure AD PTD, with reduced penetrance (60\%) and variable expressivity (Saunders-Pullman et al., 2007). DYT6-dystonia is characterized by juvenile onset and frequent generalization but, in contrast to DYT1-dystonia, cranial-cervical, and laryngeal areas are frequently involved as the starting site. Nevertheless, onset in adult age or in a limb, and lack of generalization, have all been reported (LeDoux et al., 2012). Mutations in the THAP1 (thanatos associated protein-1) gene on chromosome 8p21-p22 were initially identified in Amish-Mennonite families (Fuchs et al., 2009). Subsequently, about 60 familial and sporadic cases have been reported worldwide (Blanchard et al., 2011). Despite its dominant inheritance, a homozygous mutation in THAP1 has been described in a consanguineous family with generalized dystonia (Schneider et al., 2011). Since almost each case bears a unique mutation, molecular diagnosis requires direct sequencing of the whole THAP1 coding region.

Recently, thanks to the advent of Whole Exome Sequencing (WES) technology, four new genes have been implicated as causative of $\mathrm{AD}$ focal/segmental dystonia. In one large Australian family with fully penetrant juvenile-adult-onset "whispering dysphonia," occasional generalization and alcohol benefit (Wilcox et al., 2011), the p.R2G mutation in the TUBB4a gene (DYT4, encoding the isoform a of b-Tubulin) has been identified by exome sequencing (Hersheson et al., 2012). Molecular screening of 394 phenotypically similar patients identified a novel mutation (p.A271T) in one case (Lohmann et al., 2013). Mutations in CIZ1 (DYT23, CDKN1A-interacting zinc finger protein-1), ANO3 (DYT24, Anoctamin 3, encoding a calcium-gated chloride channel highly expressed in the striatum), and GNAL (DYT25, guanine nucleotide-binding protein, alpha-activating activity polypeptide, olfactory type), have been identified in families with juvenileadult-onset cervical or cranial-cervical dystonia and in a few sporadic cases with similar phenotypes (Charlesworth et al., 2012; Xiao et al., 2012; Fuchs et al., 2013). In particular, GNAL mutations 
were detected in additional 6 out of 39 families (15\%), suggesting they could represent a major cause of adult-onset cranial-cervical dystonia PTD.

Other AD PTD loci have been described in isolated familial cases. The DYT7 locus was mapped to chromosome $18 \mathrm{p}$ in a family with cervical PTD (Leube et al., 1996), but its existence has been recently questioned (Winter et al., 2012). The DYT13 locus was mapped to chromosome 1 p36 in an Italian family with juvenile onset dystonia, prominent cranial-cervical and arm involvement, and occasional generalization (Bentivoglio et al., 2004) while, in another family with adult-onset generalized/multifocal dystonia, often starting with blepharospasm, the DYT21 locus was mapped to 2q14.3-q21.3 (Norgren et al., 2011). For both loci, the causative gene is still missing.

\section{AUTOSOMAL RECESSIVE PTD}

Few families with AR PTD have been described to date. These include DYT2, an early-onset PTD with limb involvement and rapid generalization (Khan et al., 2003), and DYT17, a juvenile segmental/generalized dystonia with severe dysphonia mapped to chromosome 20p11.2-q13.12 in a Lebanese family (Chouery et al., 2008). The causative genes for these Mendelian PTDs still have to be identified and their detection represents a challenge to address with innovative techniques such as WES.

\section{SPORADIC LATE-ONSET PTD}

Late-onset PTD is about 10 times more frequent than early-onset PTD with an estimated prevalence of 30/100,000 worldwide [Epidemiological Study of Dystonia in Europe (ESDE) Collaborative Group, 2000]. The disease usually begins in adulthood and shows limited tendency to spread or generalize. The majority of lateonset PTD are sporadic, yet a positive family history is present in up to $25 \%$ of first-degree relatives, supporting the existence of genetic factors that could influence PTD susceptibility (Defazio et al., 2012). It is hypothesized that most cases have a multifactorial basis, in which common susceptibility genes interplay with individual genetic and environmental risk factors to reach a threshold of disease (Defazio et al., 2007).

In order to show an association between specific genetic variants and focal dystonias, many case-control studies have been performed, focusing on candidate genes such as those related to dopaminergic transmission, brain plasticity, and genes causative of Mendelian PTDs; overall, these studies have yielded contradictory outcomes. The $(\mathrm{CT} / \mathrm{GT} / \mathrm{GA})_{\mathrm{n}}$ polymorphism in the dopamine D5 receptor gene has been associated with adult-onset focal dystonia in patients of European ancestry, but not in other cohorts. Similarly, a functional polymorphism (p.V66M, rs6265) in the brain-derived neurotrophic factor (BDNF) gene and variants in the THAP1 gene have been associated to PTD risk, but with inconsistent results. More extensive work has been performed on TOR $1 A$ variants. The p.D216H SNP was reported as a risk factor in patients with familial focal/segmental dystonia, but these results were not replicated in other studies. Several SNPs from the $3^{\prime}$ untranslated region of TOR1A have also been implicated in focal dystonia as predisposing factors in some studies but protective in others. These contradictory data are likely due to confounding factors including the small number of SNPs tested, limited samples size, clinical heterogeneity of PTDs and different ethnicity (Ozelius and Bressman, 2011).

\section{NEW APPROACHES TO IMPROVE KNOWLEDGE ON PTD GENETICS}

Although 15 years have passed from the discovery of the first PTD gene (Ozelius et al., 1997), the identification of new dystonia genes has progressed slowly. This relates to the scarcity of large families with several affected members, the fragmentary knowledge about the pathogenetic mechanisms of dystonias and the difficulty in identifying clinically homogeneous families or groups of patients for genetic studies. Recently, the identification of PTD endophenotypes, the characterization of interactions between dystoniarelated proteins and the advent of innovative techniques such as WES and genome-wide association studies (GWAS), provide new hope in clarifying aspects of PTD.

\section{UNRAVELING PTD ENDOPHENOTYPES}

A major limitation in assessing PTD families is that clinical investigation is usually restricted to the motor phenotype, although non-motor features have also been detected (Stamelou et al., 2012). Recently, several studies based on neuroimaging, neurophysiological, and expression profiling approaches have reported subclinical abnormalities (endophenotypes) in healthy DYT1/DYT6 mutation carriers (Fiorio et al., 2007; Bradley et al., 2009; Walter et al., 2010; Niethammer et al., 2011; Phukan et al., 2011). For instance, magnetic resonance diffusion tensor imaging used in conjunction with probabilistic tractography have demonstrated an anatomical disruption of cerebellar outflow in all DYT1/DYT6 carriers regardless of the phenotype, while a second protective downstream alteration of thalamo-cortical projections was found in non-manifesting carriers only (Argyelan et al., 2009). FDG-PET studies have shown relative metabolic increases in presupplementary motor area and parietal association regions in DYT1/DYT6 patients and a different pattern of abnormalities in non-manifesting carriers (Carbon et al., 2004). In Raclopride-PET imaging studies, significant reductions in radioligand binding have been detected in both DYT1 and DYT6 carriers, being greater in the latter, suggesting an intriguing link between DYT6 and dopamine function (Carbon et al., 2009).

Similar approaches have been employed to detect endophenotypes among healthy relatives of patients with focal dystonias, whose genetic bases are largely unknown. For example, somatosensory spatial and temporal discrimination thresholds (TDT) have been found altered not only in focal dystonia patients (Sanger et al., 2001; Scontrini et al., 2009; Tinazzi et al., 2012) but also in some healthy family members. Interestingly in these subjects a correlation has been reported between abnormal tactile TDT and a bilateral increase in putaminal gray matter detected by Voxel Based Morphometry (Bradley et al., 2009).

Moreover, these findings may shed light on pathophysiological mechanisms underlying primary dystonias. It is now established that PTDs, traditionally regarded as a mere basal ganglia disease without structural abnormalities, might be considered a neurodevelopmental circuit disorder, in which maladaptive plasticity in the sensory-motor cortex (Quartarone et al., 2009) and impaired inhibition at different levels of the central nervous system are 
necessary to produce an overt motor manifestation (Albanese and Lalli, 2012). As it is now clear that non-motor features are part of the pathophysiological "fingerprint" of dystonia, endophenotypes could represent valuable tools for future research. In this light, neurophysiology and neuroimaging may facilitate the identification of clinically non-manifesting mutation carriers within PTD families, or may allow the clustering of homogeneous groups for genetic studies (Stamelou et al., 2012).

\section{CUES FROM PTD PATHOGENESIS}

The PTDs phenotypic variability suggests genetic heterogeneity. However clinical overlaps, not only within early-onset PTDs but also with the more common focal/segmental dystonias, suggest that common pathogenic mechanisms may be involved. Indeed, recent functional studies have demonstrated that THAP1 and TOR $1 A$ interact in a common pathway.

TorsinA, a member of the AAA+ superfamily, is involved in multiple cellular functions (vesicle fusion, membrane trafficking, protein folding, and cytoskeletal dynamics) and has a protective role by maintaining a homeostatic threshold against the endothelial reticulum (ER) stress. When mutated, its buffering capacity is greatly diminished, its ATPase activity reduced and its ER translocation prevented (Granata and Warner, 2010). Thap1 is a nuclear transcription factor that can regulate endothelial cell proliferation (Cayrol et al., 2007) but its function in the brain is still unknown. In vitro studies have shown that Thap 1 physically interacts with TOR1A and represses TorsinA expression by binding to the TOR1A promoter; this interaction is abolished by pathogenic mutations, leading to a decreased repression (Kaiser et al., 2010). However, the role of Thap1 as a major genetic modifier in DYT1-dystonia has been recently questioned (Palada et al., 2012). In line with this, Thap 1 is predicted to regulate several other gene targets, including the TAF1 gene which is also implicated in DYT3 dystonia (Mazars et al., 2010).

The identification of the novel dystonia genes are contributing to shed light on the pathogenetic mechanisms of PTD. TUBB4a is supposed to be involved in neuronal cytoskeletal defects (Hersheson et al., 2012), while ANO3 and GNAL mutations point to a key role for striatal neurons in the pathophysiology of dystonia, either through abnormal neuronal excitability related to the malfunctioning of chloride channels or through abnormalities of dopamine and/or adenosine signal transduction pathways (Charlesworth et al., 2012; Fuchs et al., 2013). However functional studies are needed in order to assess their specific role in the pathophysiology of dystonia and their potential interactions with other PTD genes.

\section{NOVEL HIGH-THROUGHPUT STRATEGIES FOR IDENTIFICATION OF PTD-RELATED GENES}

To date, the identification of PTD genes and genetic risk factors has proven to be a hard task. Recently, however, the introduction of novel high-throughput technologies (WES and GWAS) have boosted these fields (Kumar et al., 2012).

Whole exome sequencing can identify novel disease-causative genes by sequencing the entire human exome in a single experiment, and has truly revolutioned gene identification in Mendelian disorders. In the field of dystonias, the first result was seen in
Paroxysmal Kinesigenic Dyskinesia (PKD, DYT10 locus), a rare $\mathrm{AD}$ episodic dystonic syndrome characterized by recurrent and brief attacks of involuntary movements triggered by sudden voluntary movements. Overlapping phenotypes include Infantile Convulsions and Paroxysmal Choreoathetosis (ICCA) and Benign Familial Infantile Seizures syndrome (BFIS). PKD, ICCA, and other related phenotypes had been mapped to distinct loci at the pericentromeric region of chromosome 16 (Tomita et al., 1999; Swoboda et al., 2000; Valente et al., 2000), but the causative gene(s) had long been elusive. Using WES, several groups independently identified mutations in the PRRT2 gene as the major cause of PKD and ICCA syndrome (Chen et al., 2011; Wang et al., 2011; Lee et al., 2012), demonstrating the inaccuracy of mapping data. After gene identification, mutations were also identified in pure BFIS families (Ono et al., 2012), as well as in occasional cases with hemiplegic migraine (Dale et al., 2012). This confirmed that mutations in the same gene can cause heterogeneous phenotypes, suggesting a genetic complexity previously unexpected for Mendelian disorders (Schmidt et al., 2012). Subsequently, the same WES approach has been successfully used to identify four novel genes causative of late-onset PTD, as previously described.

Genome-wide association studies, on the other hand, aim at identifying polymorphic variants acting as risk factors for complex diseases via large-scale, population-based studies. Thousands of common variants (minor allele frequency $>5 \%$ ) can be simultaneously genotyped in large cohorts of patients and controls, followed by a stringent statistical analysis to discriminate real hits from false positive results. In movement disorders, this approach has been largely adapted to PD, although the number of significant hits has been unexpectedly low and only few genes, such as SNCA, MAPT, and LRRK2, have been found to harbor variants robustly associated with the disease. A recent meta-analysis of GWAS studies in PD identified 17 additional disease risk loci which surpassed the threshold for genome-wide significance, all with low odds ratios (Kumar et al., 2012). To date there are no published GWAS for PTDs, but their potential contribution to the field is so obvious that many such projects are currently in progress. It is expected that the new insights on PTD endophenotypes and the possibility to integrate worldwide data with a meta-analytic approach, are going to shrink some of the confounding factors that could have compromised previous association studies.

\section{MERGING PAST AND FUTURE: GENETIC AND COUNSELING IN PTDs}

Diagnosis of dystonia is mainly clinical, yet genetic analysis and counseling is being requested more and more often. In primary dystonias, genetic testing is only available for those forms of earlyonset PTD for which the gene is known (Figure 1). Testing of the DYT1-delGAG, that is readily available and relatively inexpensive, should be recommended for any PTD case with onset before 26 years and in those with later onset who have an affected relative with early-onset dystonia. Other TOR1A mutations are extremely rare and whole gene sequencing is not recommended in clinical practice (Albanese et al., 2011). Sequencing of the other known PTD genes (THAP1, TUBB4a, CIZ1, ANO3, and GNAL) should 


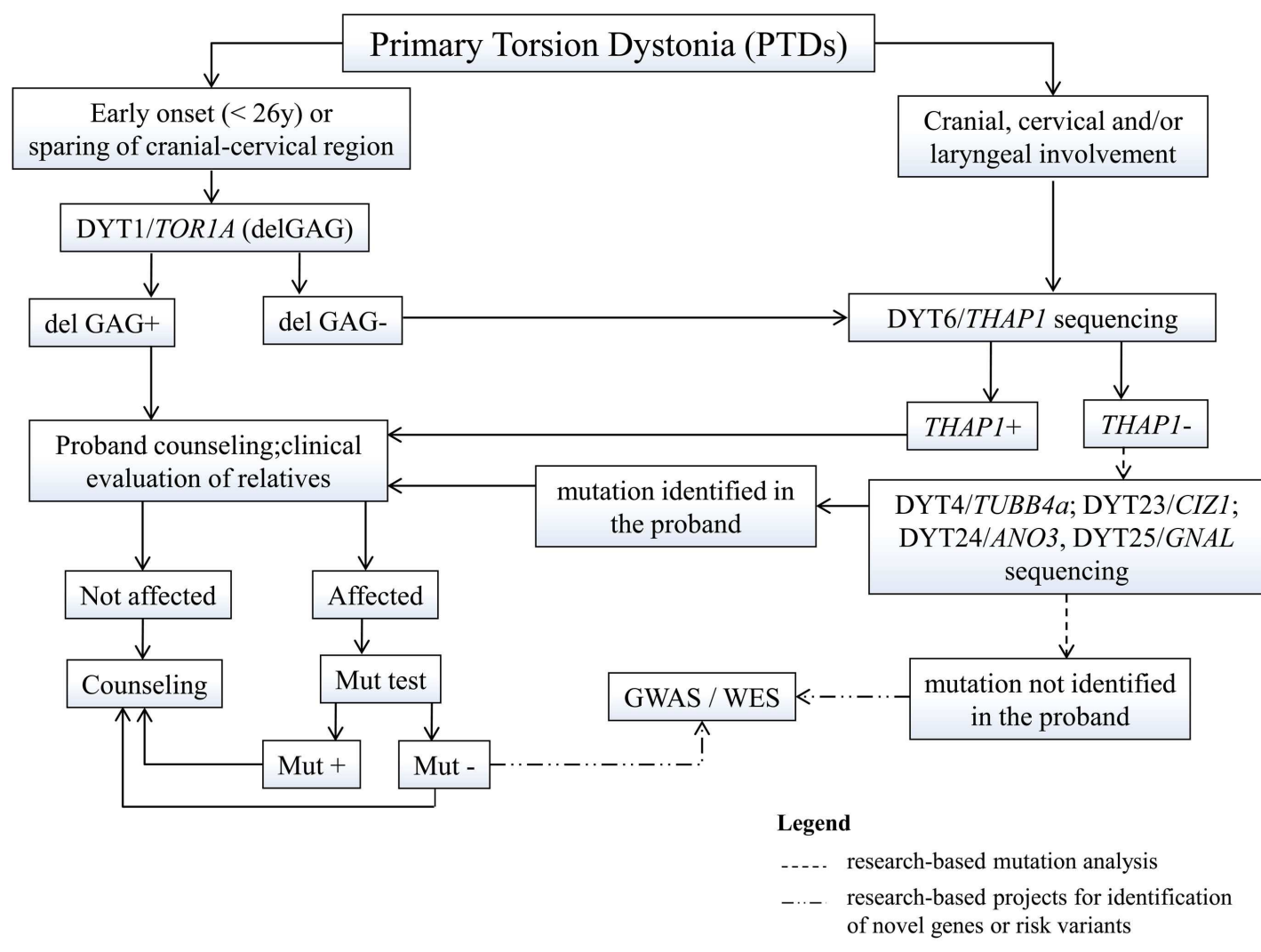

FIGURE 1 | Proposed flowchart for genetic testing in primary dystonias. GWAS, genome-wide association studies; WES, whole exome sequencing; mut, mutation.

be considered in patients with predominant cranial-cervical and laryngeal involvement, especially if family history is positive, with prioritization according to the age at onset and distribution of dystonia.

The identification of mutations in a proband requires a detailed assessment of family history, given their dominant inheritance and variable expression. Once a mutation is identified in a proband, carrier testing is available for at-risk asymptomatic relatives who may request it. This type of testing should never be performed on minors and should always be accompanied by pre-test genetic counseling. Since most PTD mutations show reduced penetrance, it is impossible to predict whether a mutation carrier will develop the disease, although such probability will progressively decrease with age, especially for early-onset conditions such as DYT1 and DYT6. Yet, in case of positive testing, they need to understand the $50 \%$ risk to transmit the mutation to their offspring

\section{REFERENCES}

Albanese, A., Asmus, F., Bhatia, K. P., Elia, A. E., Elibol, B., Filippini, G., et al. (2011). EFNS guidelines on diagnosis and treatment of primary dystonias. Eur. J. Neurol. 18, 5-18.

Albanese, A., and Lalli, S. (2012). Update on dystonia. Curr. Opin. Neurol. 25, 483-490.
Argyelan, M., Carbon, M., Niethammer, M., Ulug, A. M., Voss, H. U., Bressman, S. B., et al. (2009). Cerebellothalamocortical connectivity regulates penetrance in dystonia. J. Neurosci. 29, 9740-9747.

Bentivoglio, A. R., Ialongo, T., Contarino, M. F., Valente, E. M., and Albanese, A. (2004). Phenotypic

who could eventually develop the disease, based on estimated penetrance.

Genetic diagnosis in sporadic late-onset PTD is much more complex as several genetic and environmental factors are likely to be involved. GWAS are significantly improving our understanding of the complexity of sporadic PTDs, allowing the identification of genetic susceptibility or protective factors for the development of the disease. Yet, to avoid false expectation from commercially available genetic profiles, it should be remembered that such genetic factors are relevant only in large population studies, while they are of limited significance in personalized medicine (Kumar et al., 2012).

\section{ACKNOWLEDGMENTS}

This work was supported by the Italian Ministry of Health (Ricerca Corrente 2012).

characterization of DYT13 primary torsion dystonia. Mov. Disord. 19, 200-206.

Blanchard, A., Ea, V., Roubertie, A., Martin, M., Coquart, C., Claustres, M., et al. (2011). DYT6 dystonia: review of the literature and creation of the UMD Locus-Specific Database (LSDB) for mutations in the THAP1 gene. Hum. Mutat. 32, 1213-1224.

Bradley, D., Whelan, R., Walsh, R., Reilly, R. B., Hutchinson, S., Molloy, F. et al. (2009). Temporal discrimination threshold: VBM evidence for an endophenotype in adult onset primary torsion dystonia. Brain 132, 2327-2335 
Bressman, S. B. (2004). Dystonia genotypes, phenotypes, and classification. Adv. Neurol. 94, 101-107.

Bressman, S. B., Sabatti, C., Raymond, D., De Leon, D., Klein, C., Kramer, P. L., et al. (2000). The DYT1 phenotype and guidelines for diagnostic testing. Neurology 54, 1746-1752.

Calakos, N., Patel, V. D., Gottron, M., Wang, G., Tran-Viet, K. N., Brewington, D., et al. (2010). Functional evidence implicating a novel TOR1A mutation in idiopathic, late-onset focal dystonia. J. Med. Genet. 47, 646-650.

Carbon, M., Niethammer, M., Peng, S., Raymond, D., Dhawan, V., Chaly, T., et al. (2009). Abnormal striatal and thalamic dopamine neurotransmission: genotype-related features of dystonia. Neurology 72, 2097-2103.

Carbon, M., Su, S., Dhawan, V., Raymond, D., Bressman, S., and Eidelberg, D. (2004). Regional metabolism in primary torsion dystonia: effects of penetrance and genotype. Neurology 62, 1384-1390.

Cayrol, C., Lacroix, C., Mathe, C., Ecochard, V., Ceribelli, M., Loreau, E., et al. (2007). The THAPzinc finger protein THAP1 regulates endothelial cell proliferation through modulation of $\mathrm{pRB} / \mathrm{E} 2 \mathrm{~F}$ cell-cycle target genes. Blood 109, 584-594.

Charlesworth, G., Plagnol, V., Holmstrom, K. M., Bras, J., Sheerin, U. M., Preza, E., et al. (2012). Mutations in ANO3 cause dominant craniocervical dystonia: ion channel implicated in pathogenesis. Am. J. Hum. Genet. 91, 1041-1050.

Chen, W. J., Lin, Y., Xiong, Z. Q., Wei, W., Ni, W., Tan, G. H., et al. (2011). Exome sequencing identifies truncating mutations in PRRT2 that cause paroxysmal kinesigenic dyskinesia. Nat. Genet. 43, 1252-1255.

Chouery, E., Kfoury, J., Delague, V., Jalkh, N., Bejjani, P., Serre, J. L., et al. (2008). A novel locus for autosomal recessive primary torsion dystonia (DYT17) maps to 20p11.22-q13.12. Neurogenetics 9, 287-293.

Dale, R. C., Gardiner, A., Antony, J., and Houlden, H. (2012). Familial PRRT2 mutation with heterogeneous paroxysmal disorders including paroxysmal torticollis and hemiplegic migraine. Dev. Med. Child Neurol. 54, 958-960.

Defazio, G., Abbruzzese, G., Girlanda, P., Liguori, R., Santoro, L., Tinazzi, M., et al. (2012). Phenotypic overlap in familial and sporadic primary adult-onset extracranial dystonia. J. Neurol. 259, 2414-2418.
Defazio, G., Berardelli, A., and Hallett, M. (2007). Do primary adult-onset focal dystonias share aetiological factors? Brain 130, 1183-1193.

Edwards, M., Wood, N., and Bhatia, K. (2003). Unusual phenotypes in DYT1 dystonia: a report of five cases and a review of the literature. Mov. Disord. 18, 706-711.

Epidemiological Study of Dystonia in Europe (ESDE) Collaborative Group. (2000). A prevalence study of primary dystonia in eight European countries. J. Neurol. 247, 787-792.

Fahn, S. (1988). Concept and classification of dystonia. Adv. Neurol. 50, $1-8$.

Fiorio, M., Gambarin, M., Valente, E. M., Liberini, P., Loi, M., Cossu, G., et al. (2007). Defective temporal processing of sensory stimuli in DYT1 mutation carriers: a new endophenotype of dystonia? Brain 130, 134-142.

Fuchs, T., Gavarini, S., SaundersPullman, R., Raymond, D., Ehrlich, M. E., Bressman, S. B., et al. (2009). Mutations in the THAP1 gene are responsible for DYT6 primary torsion dystonia. Nat. Genet. 41, 286-288.

Fuchs, T., Saunders-Pullman, R., Masuho, I., Luciano, M. S., Raymond, D., Factor, S., et al. (2013). Mutations in GNAL cause primary torsion dystonia. Nat. Genet. 45, 88-92.

Granata, A., and Warner, T. T. (2010). The role of torsinA in dystonia. Eur. J. Neurol. 17(Suppl. 1), 81-87.

Hersheson, J., Mencacci, N. E., Davis, M., Macdonald, N., Trabzuni, D., Ryten, M., et al. (2012). Mutations in the autoregulatory domain of betatubulin 4 a cause hereditary dystonia. Ann. Neurol. doi:10.1002/ana.23832. [Epub ahead of print]

Kaiser, F. J., Osmanoric, A., Rakovic, A., Erogullari, A., Uflacker, N., Braunholz, D., et al. (2010). The dystonia gene DYT1 is repressed by the transcription factor THAP1 (DYT6). Ann. Neurol. 68, 554-559.

Kamm, C., Fischer, H., Garavaglia, B., Kullmann, S., Sharma, M., Schrader, C., et al. (2008). Susceptibility to DYT1 dystonia in European patients is modified by the $\mathrm{D} 216 \mathrm{H}$ polymorphism. Neurology 70, 2261-2262.

Khan, N. L., Wood, N. W., and Bhatia, K. P. (2003). Autosomal recessive, DYT2-like primary torsion dystonia: a new family. Neurology 61, 1801-1803.

Klein, C., Brin, M. F., De Leon, D., Limborska, S. A., Ivanova-Smolenskaya, I. A., Bressman, S. B., et al. (1998).
De novo mutations (GAG deletion) in the DYT1 gene in two non-Jewish patients with earlyonset dystonia. Hum. Mol. Genet. 7 , 1133-1136.

Kumar, K. R., Lohmann, K., and Klein, C. (2012). Genetics of Parkinson disease and other movement disorders. Curr. Opin. Neurol. 25, 466-474.

LeDoux, M. S., Xiao, J., Rudzinska, M., Bastian, R. W., Wszolek, Z. K., Van Gerpen, J. A., et al. (2012). Genotype-phenotype correlations in THAP1 dystonia: molecular foundations and description of new cases. Parkinsonism Relat. Disord. 18, 414-425.

Lee, H. Y., Huang, Y., Bruneau, N., Roll, P., Roberson, E. D., Hermann, M., et al. (2012). Mutations in the gene PRRT2 cause paroxysmal kinesigenic dyskinesia with infantile convulsions. Cell Rep. 1, 2-12.

Leube, B., Rudnicki, D., Ratzlaff, T. Kessler, K. R., Benecke, R., and Auburger, G. (1996). Idiopathic torsion dystonia: assignment of a gene to chromosome $18 \mathrm{p}$ in a German family with adult onset, autosomal dominant inheritance and purely focal distribution. Hum. Mol. Genet. 5, 1673-1677.

Lohmann, K., Wilcox, R. A., Winkler, S., Ramirez, A., Rakovic, A., Park, J. S., et al. (2013). Whispering dysphonia (DYT4 dystonia) is caused by a mutation in the TUBB4 gene. Ann. Neurol. doi:10.1002/ana.23829

Mazars, R., Gonzalez-De-Peredo, A., Cayrol, C., Lavigne, A. C., Vogel, J. L., Ortega, N., et al. (2010). The THAP-zinc finger protein THAP1 associates with coactivator HCF1 and O-GlcNAc transferase: a link between DYT6 and DYT3 dystonias. J. Biol. Chem. 285, 13364-13371.

Niethammer, M., Carbon, M., Argyelan, M., and Eidelberg, D. (2011) Hereditary dystonia as a neurodevelopmental circuit disorder: evidence from neuroimaging. Neurobiol. Dis. 42, 202-209.

Norgren, N., Mattson, E., Forsgren, L., and Holmberg, M. (2011). A high-penetrance form of late-onset torsion dystonia maps to a novel locus (DYT21) on chromosome 2q14.3-q21.3. Neurogenetics 12, 137-143.

Ono, S., Yoshiura, K., Kinoshita, A. Kikuchi, T., Nakane, Y., Kato, N., et al (2012). Mutations in PRRT2 responsible for paroxysmal kinesigenic dyskinesias also cause benign familial infantile convulsions. J. Hum. Genet. 57, 338-341.
Opal, P., Tintner, R., Jankovic, J., Leung, J., Breakefield, X. O., Friedman, J., et al. (2002). Intrafamilial phenotypic variability of the DYT1 dystonia: from asymptomatic TOR1A gene carrier status to dystonic storm. Mov. Disord. 17, 339-345.

Ozelius, L. J., and Bressman, S. B. (2011). Genetic and clinical features of primary torsion dystonia. Neurobiol. Dis. 42, 127-135.

Ozelius, L. J., Hewett, J. W., Page, C. E., Bressman, S. B., Kramer, P. L., Shalish, C., et al. (1997). The earlyonset torsion dystonia gene (DYT1) encodes an ATP-binding protein. Nat. Genet. 17, 40-48.

Palada, V., Stiern, S., Glockle, N., Gomez-Garre, P., Carrillo, F., Mir, P. et al. (2012). Lack of sequence variations in THAP1 gene and THAP1binding sites in TOR1A promoter of DYT1 patients. Mov. Disord. 27, 917.

Phukan, J., Albanese, A., Gasser, T., and Warner, T. (2011). Primary dystonia and dystonia-plus syndromes: clinical characteristics, diagnosis, and pathogenesis. Lancet Neurol. 10, 1074-1085.

Quartarone, A., Rizzo, V., Terranova, C., Morgante, F., Schneider, S., Ibrahim, N., et al. (2009). Abnormal sensorimotor plasticity in organic but not in psychogenic dystonia. Brain 132, 2871-2877.

Sanger, T. D., Tarsy, D., and PascualLeone, A. (2001). Abnormalities of spatial and temporal sensory discrimination in writer's cramp. Mov. Disord. 16, 94-99.

Saunders-Pullman, R., Raymond, D., Senthil, G., Kramer, P., Ohmann, E., Deligtisch, A., et al. (2007). Narrowing the DYT6 dystonia region and evidence for locus heterogeneity in the Amish-Mennonites. Am. J. Med. Genet. A 143A, 2098-2105.

Schmidt, A., Kumar, K. R., Redyk, K., Grunewald, A., Leben, M., Munchau, A., et al. (2012). Two faces of the same coin: benign familial infantile seizures and paroxysmal kinesigenic dyskinesia caused by PRRT2 mutations. Arch. Neurol. 69, 668-670.

Schneider, S. A., Ramirez, A., Shafiee, K., Kaiser, F. J., Erogullari, A., Bruggemann, N., et al. (2011). Homozygous THAP1 mutations as cause of early-onset generalized dystonia. Mov. Disord. 26, 858-861.

Scontrini, A., Conte, A., Defazio, G., Fiorio, M., Fabbrini, G., Suppa, A., et al. (2009). Somatosensory temporal discrimination in patients with primary focal dystonia. J. Neurol. Neurosurg. Psychiatr. 80, 1315-1319. 
Stamelou, M., Edwards, M. J., Hallett, M., and Bhatia, K. P. (2012). The non-motor syndrome of primary dystonia: clinical and pathophysiological implications. Brain 135, 1668-1681.

Swoboda, K. J., Soong, B., Mckenna, C., Brunt, E. R., Litt, M., Bale, J. F. Jr., et al. (2000). Paroxysmal kinesigenic dyskinesia and infantile convulsions: clinical and linkage studies. Neurology 55, 224-230.

Tinazzi, M., Fasano, A., Di Matteo, A., Conte, A., Bove, F., Bovi, T., et al. (2012). Temporal discrimination in patients with dystonia and tremor and patients with essential tremor. Neurology 80, 76-84.

Tomita, H., Nagamitsu, S., Wakui, K., Fukushima, Y., Yamada, K., Sadamatsu, M., et al. (1999). Paroxysmal kinesigenic choreoathetosis locus maps to chromosome 16p11.2-q12.1. Am. J. Hum. Genet. 65, 1688-1697.
Valente, E. M., Spacey, S. D., Wali, G. M., Bhatia, K. P., Dixon, P. H., Wood, N. W., et al. (2000). A second paroxysmal kinesigenic choreoathetosis locus (EKD2) mapping on 16q13q22.1 indicates a family of genes which give rise to paroxysmal disorders on human chromosome 16. Brain 123(Pt 10), 2040-2045.

Walter, M., Bonin, M., Pullman, R. S., Valente, E. M., Loi, M., Gambarin, M., et al. (2010). Expression profiling in peripheral blood reveals signature for penetrance in DYT1 dystonia. Neurobiol. Dis. 38, 192-200.

Wang, J. L., Cao, L., Li, X. H., Hu, Z. M., Li, J. D., Zhang, J. G., et al. (2011). Identification of PRRT2 as the causative gene of paroxysmal kinesigenic dyskinesias. Brain 134, 3493-3501.

Wilcox, R. A., Winkler, S., Lohmann, K., and Klein, C. (2011). Whispering dysphonia in an Australian family (DYT4): a clinical and genetic reappraisal. Mov. Disord. 26, 2404-2408.
Winter, P., Kamm, C., Biskup, S., Kohler, A., Leube, B., Auburger, G., et al. (2012). DYT7 gene locus for cervical dystonia on chromosome $18 \mathrm{p}$ is questionable. Mov. Disord. 27, 1819-1821.

Xiao, J., Uitti, R. J., Zhao, Y., Vemula, S. R., Perlmutter, J. S., Wszolek, Z. K., et al. (2012). Mutations in CIZ1 cause adult onset primary cervical dystonia. Ann. Neurol. 71, 458-469.

Zirn, B., Grundmann, K., Huppke, P., Puthenparampil, J., Wolburg, H., Riess, O., et al. (2008). Novel TOR1A mutation p.Arg288Gln in early-onset dystonia (DYT1). J. Neurol. Neurosurg. Psychiatr. 79, 1327-1330.

Conflict of Interest Statement: Prof. Valente serves on the editorial boards of BMC Neurology, Movement Disorders, and Pediatric Research. She is the recipient of a European Research Council Starting Grant, and of research grants from the Italian Ministry of Health, the Italian Ministry of University and Research, the Telethon Foundation Italy and the European Community FP7 Program.

Received: 08 October 2012; accepted: 27 March 2013; published online: 10 April 2013.

Citation: Petrucci $S$ and Valente EM (2013) Genetic issues in the diagnosis of dystonias. Front. Neurol. 4:34. doi: 10.3389/fneur.2013.00034

This article was submitted to Frontiers in Movement Disorders, a specialty of Frontiers in Neurology.

Copyright (c) 2013 Petrucci and Valente. This is an open-access article distributed under the terms of the Creative Commons Attribution License, which permits use, distribution and reproduction in other forums, provided the original authors and source are credited and subject to any copyright notices concerning any third-party graphics etc. 